\title{
Evaluation of egg parasitoid Hadronotus pennsylvanicus as a prospective biocontrol agent of the leaffooted bug Leptoglossus zonatus
}

\author{
Robert K. Straser $(\mathbb{D}) \cdot$ Kent M. Daane $(\mathbb{D}) \cdot$ Elijah Talamas $(\mathbb{D} \cdot$ Houston Wilson $(\mathbb{D}$
}

Received: 8 June 2021 / Accepted: 14 January 2022 / Published online: 24 January 2022

(C) The Author(s) 2022

\begin{abstract}
The western leaffooted bug, Leptoglossus zonatus (Dallas) (Heteroptera: Coreidae), is a key pest of almonds and pistachios in the USA. With limited monitoring strategies and no economic threshold developed, the use of broad-spectrum insecticides remains the primary control tactic for $L$. zonatus. In pursuit of more sustainable management options, experiments were carried out to assess the biocontrol potential of the egg parasitoid Hadronotus pennsylvanicus (Ashmead) (Hymenoptera: Scelionidae) against L. zonatus. Biological and demographical attributes of $H$. pennsylvanicus were evaluated under controlled laboratory conditions. Mated females lived on average 116 days. However, female longevity declined by $74 \%$ when provided with host eggs, and
\end{abstract}

Handling Editor: Dirk Babendreier.

R. K. Straser $(\varangle) \cdot$ H. Wilson

Department of Entomology, University of California,

Riverside, 900 University Ave., Riverside,

CA 92521, USA

e-mail: rstra005@ucr.edu

K. M. Daane

Department of Environmental Science, Policy and Management, University of California, Berkeley, Mulford

Hall \#3114, Berkeley, CA 94720-3114, USA

E. Talamas

Florida Department of Agriculture and Consumer

Services, 1911 SW 34th St., Gainesville,

FL 32608, USA by $97 \%$ when deprived of a suitable diet. Females produced an average 39.70 offspring, with peak fecundity observed within the first week of their lifespan. The total progeny was on average $92.75 \%$ female. Non-reproductive host mortality accounted for $>52 \%$ of the total egg mortality observed within the first two weeks, and represented the majority of total host egg mortality thereafter. Age of host eggs did not influence parasitism rates. Under laboratory conditions, $H$. pennsylvanicus exhibits suitable demographic and reproductive traits as a candidate biocontrol agent of $L$. zonatus. Further research is needed to determine how to best manipulate and enhance $H$. pennsylvanicus populations to promote biocontrol of L. zonatus under field conditions.

Keywords Hadronotus pennsylvanicus . Hymenoptera · Scelionidae - Leptoglossus zonatus . Heteroptera $\cdot$ Coreidae

\section{Introduction}

The western leaffooted bug, Leptoglossus zonatus (Dallas) (Hemiptera: Coreidae), is a polyphagous pest native to the Western Hemisphere (Brailovsky 2014), and known to attack diverse economically important crops (Grimm 1999; Rivero and Hernández 2009; Xiao and Fadamiro 2010; Foresti et al. 2017; Joyce 
et al. 2017). Feeding from $L$. zonatus can result in crop damage and reduced yields, as documented for crops such as satsuma mandarin, Citrus unshiu (Xiao and Fadamiro 2010), and seed corn, Zea mays (Marchiori et al. 2002). In California's Central Valley, USA, $L$. zonatus has been reported as an occasional pest to tree nut crops, such as almond and pistachio (Daane et al. 2005). However, with the increased acreage of these nut crops over the past two decades, the pest is becoming more problematic for growers (Daane et al. 2016; Joyce et al. 2017; Zalom et al. 2018). L. zonatus has the potential to cause significant damage to nut crops, including epicarp lesions and kernel necrosis, and can facilitate fungal contaminations including stigmatomycosis and Botryosphaeria infection (Michailides et al. 1987; Michailides 1989; Michailides and Morgan 2016; Daane et al. 2005; Joyce et al. 2019; Stahl et al. 2020). Unlike smaller hemipteran pests, damage inflicted by $L$. zonatus can result in kernel damage throughout the growing season (Daane et al. 2016).

Current methods for monitoring $L$. zonatus in orchards include beat-tray sampling of the tree canopy and visual assessment of developing nuts for feeding damage (Daane et al. 2016; Zalom et al. 2018). However, with no existing economic thresholds associated with these monitoring efforts, such tactics can be time and labor intensive while providing limited information on true pest densities or associated crop damage. Given the lack of effective monitoring tools, along with grower aversion to risk from early season feeding damage, broad-spectrum insecticides such as pyrethroids remain the primary control tactic for $L$. zonatus (Haviland et al. 2018; Zalom et al. 2018). With increasing demand for more sustainable pest management options, growers have expressed interest in exploring alternative control tactics to improve current integrated pest management (IPM) programs for L. zonatus in tree nut crops.

Egg parasitoids have demonstrated potential as effective biocontrol agents in crop landscapes given their relative host specificity, efficiency in host searching, and ability to suppress pest populations (Abram et al. 2020). One of the most prominent egg parasitoids of Leptoglossus spp. is Hadronotus pennsylvanicus (previously reported as Gryon pennsylvanicum) (Ashmead) (Hymenoptera: Scelionidae) (Masner 1983; Marchiori 2002; Bates and Borden 2004; Maltese et al. 2012). H. pennsylvanicus is a synovigenic, solitary endoparasitoid of several coreid hosts and has been the focus of many biocontrol programs for agricultural pests, including Anasa tristis (DeGeer) (Nechols et al. 1989), Leptoglossus phyllopus (L.) (Mitchell and Mitchell 1986), L. australis Fabricius (Yasuda 1998), and L. occidentalis Heidemann (Bates and Borden 2004; Maltese et al. 2012; Roversi et al. 2013). Under laboratory conditions, $H$. pennsylvanicus exhibits desirable biological and reproductive traits as a biocontrol agent to A. tristis (Nechols et al. 1989) and L. occidentalis (Sabbatini Peverieri et al. 2012). In controlled settings, $H$. pennsylvanicus can exhibit a high fecundity rate (80.7 eggs per female, A. tristis host; 144.6 eggs per female, L. occidentalis host), high sex ratio (78\% female, A. tristis host; $72 \%$ female, L. occidentalis host) and long lifespan when under reproductive opportunity (35.3 days, A. tristis host; 40.27 days, $L$. occidentalis host) (Nechols et al. 1989; Sabbatini Peverieri et al. 2012). However, little is known about how such demographic and reproductive parameters on A. tristis and L. occidentalis may translate to successful biocontrol of $L$. zonatus specifically.

The life history traits of a candidate natural enemy determine its prospects as a successful biocontrol agent. In the present study, the reproductive and developmental biology of $H$. pennsylvanicus on $L$. zonatus was investigated under laboratory conditions, and parasitoid viability was assessed on host eggs of varying ages. The results of this study highlight the prospects and limitations of egg parasitoid H. pennsylvanicus as a candidate biocontrol agent of agricultural pest $L$. zonatus.

\section{Methods}

Experimental conditions

Laboratory colonies of $H$. pennsylvanicus and $L$. zonatus were reared from specimens collected in 2017 from Fresno County, California, USA. The L. zonatus strain was collected from pomegranates and replenished with wild specimens ad libitum. Insects were maintained in cages $(60 \mathrm{~cm} \times 60 \mathrm{~cm} \times 60 \mathrm{~cm}$, $680 \mu \mathrm{m}$ mesh, BugDORM ${ }^{\circ}$, Taiwan) and fed a diet of zucchini (Cucurbita pepo L.), green beans (Phaseolus vulgaris L.) and organic raw sunflower seeds (Helianthus annuus L.) replenished weekly. 
Enclosures contained a 2.361 potted juniper (Juniperus sp. L.) and wooden skewers were used as oviposition substrate. Newly laid egg clusters were collected daily for parasitoid bioassays. H. pennsylvanicus colonies were established from parasitized sentinel L. zonatus eggs in pistachio and refreshed with wild strain individuals in 2019 and 2020. Colonies were housed in $50 \mathrm{ml}$ plastic tubes (Falcon Conical Centrifuge Tubes, Fisher Scientific $\left.{ }^{\circledR}\right)$ closed at the open end with $250 \mu \mathrm{m}$ mesh to allow a permeable feeding substrate. A diet of honey-water solution (1:1) (Organic Honey, Wholesome ${ }^{\circledR}$ ) was provided ad libitum to colony. All bioassays were conducted in controlled laboratory conditions of $25{ }^{\circ} \mathrm{C} \pm 1,75 \pm 5 \% \mathrm{RH}$ and L:D 16:8 photoperiod. Observations and dissections were conducted using a Leica ${ }^{\circledR}$ S9i Stereo Microscope and BioQuip ${ }^{\circledR}$ Micro Dissection Kit. H. pennsylvanicus was identified using the key to species in the revision of Gryon Haliday by Masner (1983), and specimens were compared to images of the holotype specimen, Telenomus pennsylvanicus Ashmead. A recent analysis by Talamas et al. (2021) found Gryon to be polyphyletic and resurrected the genus Hadronotus Förster for many of the species previously placed in Gryon, including $H$. pennsylvanicus. The $\mathrm{CO} 1$ barcoding region was sequenced from a colony specimen with DNA extracted non-destructively, amplified and sequenced using the primers and methods of Ramírez-Ahuja et al. (2020), and the sequence was deposited in GenBank (MZ129311). Voucher specimens of H. pennsylvanicus were deposited in the Entomology Research Museum at the University of California, Riverside, USA, and the Florida State Collection of Arthropods, Gainesville, Florida, USA.

\section{Parasitoid longevity and lifetime fecundity}

To measure adult longevity and fecundity of $H$. pennsylvanicus, newly emerged $(<24 \mathrm{~h})$ males and females $(n=120)$ were housed in mating pairs in $10 \mathrm{ml}$ plastic tubes closed with a $250 \mu \mathrm{m}$ mesh cap. Tubes with mating pairs were randomly assigned to one of the following treatments: (1) water and 25 fresh ( $<72 \mathrm{~h})$ L. zonatus host eggs ("water \& host"; $\mathrm{n}=20$ ), (2) honey-water solution and 25 fresh host eggs ("honey-water \& host"; n = 20), or (3) honeywater solution and no host eggs ("honey-water"; $\mathrm{n}=20$ ). Diet and host eggs were replenished every other day until the female wasp expired. A new male specimen was introduced to the tube to replace any expired males to maintain copulation potential throughout the study. Data collected on male survival only consisted of the initial individuals provided at the start of each mating pair. Following $24 \mathrm{~h}$ exposure to the parasitoids, host eggs were removed, stored under laboratory conditions and observed daily for the emergence of a parasitoid or L. zonatus nymph. Eggs that neither hatched nor yielded a parasitoid after 30 days were dissected to examine for the presence of a dead nymph, dead parasitoid, or were determined aborted if neither occurred. The number of eggs and frequency of host-egg exposure to parasitoids were selected based on maximum parasitism observed within $24 \mathrm{~h}$, and previous findings that parasitism rates were unaffected when wasps was deprived of host eggs for up to five days (Vogt and Nechols 1993; Peverieri et al. 2013). Similarly, no oocycte absorption was observed when wasps were deprived of host eggs for five days (Vogt and Nechols 1993).

Parasitoid host age viability

Given that host egg age may influence parasitism behavior and oviposition, we assessed the effect of egg age on $H$. pennsylvanicus parasitism rates. Newly laid $(<24 \mathrm{~h})$ egg clusters were collected from L. zonatus colonies and stored under controlled laboratory conditions. Egg clusters were standardized to contain 25 eggs and prepared for ages 1,2, 4, or 8 day treatments ( $n=15$ for each treatment). Age treatments were selected based on the observed 10.9 day average duration for development from oviposition to first instar under similar environmental conditions (Daane et al. 2019). Egg cluster treatments were exposed individually to a randomly selected, fed, $<24 \mathrm{~h}$ old mated female wasp. Adult females were house for $24 \mathrm{~h}$ with multiple $<24 \mathrm{~h}$ old males prior to being supplied a host egg cluster. Egg clusters were removed after $24 \mathrm{~h}$ exposure to a female wasp and maintained under laboratory conditions. Clusters were observed daily for the emergence of either parasitoid or $L$. zonatus nymphs. All remaining eggs after 30 days were dissected to determine presence of a dead nymph, dead parasitoid, or identified as aborted if neither occurred. Observations from dissections did not account for the presence or absence of a parasitoid meconium. 
Non-reproductive host mortality

To evaluate the potential role non-reproductive host mortality has in L. zonatus biocontrol, we compared the proportion of aborted eggs to the total host egg mortality observed from lifetime fecundity assays. To evaluate the influence parasitoid presence has on nonreproductive host mortality, 20 fresh $(<72 \mathrm{~h}$ old $)$ unexposed $L$. zonatus egg clusters containing 25 eggs were isolated congruently with day 1 replicates from female fecundity assays. Egg clusters were housed in $10 \mathrm{ml}$ plastic tubes closed with a $250 \mu \mathrm{m}$ mesh and stored under controlled laboratory conditions for 30 days. Egg clusters were observed for the emergence of $L$. zonatus nymphs and unemerged eggs remaining were dissected to determine presence of dead nymphs or identified as aborted if contents were indiscernible following dissection.

Life table, demographic parameters and statistical analysis

Observations on age-specific survival, longevity and fecundity were used to calculate life table parameters for $H$. pennsylvanicus $\left(r_{m}\right.$, intrinsic rate of increase; $\lambda$, finite rate of increase; $T$, mean generation time; $T_{d}$, doubling time; $R_{O}$, net reproductive rate; $G R R$, gross reproductive rate) (see Sabbatini Peverieri et al. 2012). The effect of diet and host presence on adult longevity was assessed using a generalized linear mixed model (GLMM) with a gamma distribution and identity link function, testing for an interaction between "sex" and "treatment" with treatments as fixed effects. Influence of host egg age on parasitism viability was evaluated using a GLMM with binomial distribution and logit link function. The influence of female age on progeny sex ratio was assessed using a GLMM with binomial distribution and logit link function. The effect of host egg exposure to a parasitoid on proportion of aborted eggs was evaluated using a GLMM with binomial distribution and logit link function with "host presence" as a fixed effect. Replicates were included as a random effect in all statistical models. Analyses were carried out with R version 3.6.1 (R Core Team 2019). GLMM analyses were conducted using the "glmer" function in the "Ime4" package (Bates et al. 2015). Fixed effects were evaluated through model comparisons using likelihood ratio tests via the "drop1" function. When multilevel variables were found to be significant, means were separated using a post-hoc Tukey test using the "glht" function in the "multcomp" package (Hothorn et al. 2008). All data are presented as mean $\pm \mathrm{SE}$.

\section{Results}

Parasitoid longevity and lifetime fecundity

Diet significantly influenced the longevity of adult $H$. pennsylvanicus $\left(\chi^{2}=16.05, \mathrm{df}=2, \mathrm{p}<0.001\right)$ (Fig. 1). Water-fed males and females provided host eggs lived an average of $2.54 \pm 0.20$ and $2.90 \pm 0.30$ days, respectively. For honey-water fed females, there was a $74 \%$ reduction in longevity when individuals were provided host eggs. Honey-water fed females lived an average $116.00 \pm 1.81$ days in the absence of host eggs, as opposed to $30.60 \pm 3.10$ days when provided host eggs. Similarly, males fed a honey-water diet lived $97.30 \pm 1.23$ days in the absence of host eggs and $43.50 \pm 2.12$ days when provided host eggs, a $55 \%$ reduction in longevity. Females lived significantly fewer days than males only when provided with honey-water diet and host eggs (Tukey test, $\mathrm{df}=5, \mathrm{p}<0.01$ ). Males and females provided host eggs and fed a water diet began dying on

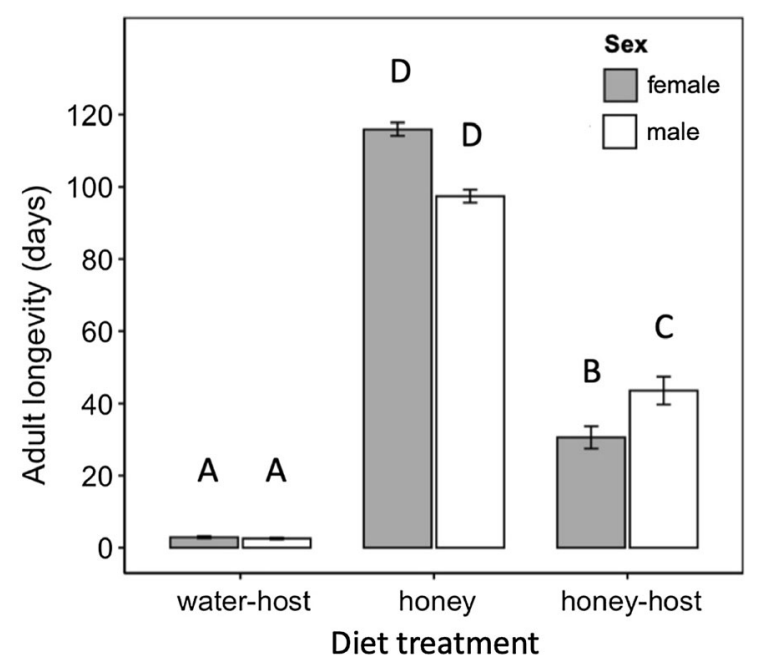

Fig. 1 Mean longevity ( \pm SE) of adult female (grey bars) and male (white bars) Hadronotus pennsylvanicus when reared with water and host eggs, honey-water and host eggs, or honey-water only. All bars indicating different letters are significantly different from one another $(\mathrm{p}<0.05)$ GLM and Tukey posthoc tests) 
day 1 of the study, with complete mortality reached on day 3 and day 6 , respectively. When fed honey-water and provided host eggs, females started dying on day 9 , reaching $50 \%$ mortality by day 25 , and surviving up to 55 days. Males began dying after 21 days, reaching $50 \%$ mortality after day 43 , and surviving up to 61 days. When fed honey-water in the absence of host eggs, males started dying after 85 days, living up to 105 days, while females began dying after 105 days and surviving up to 135 days. When honey fed females were provided a continuous supply of host eggs, $79 \%$ of all parasitism occurred within the first week of the female's lifetime (Fig. 2). The highest mean parasitism rates observed, indicated as the number of offspring produced per female per day, was on day 1 , averaging $12.25 \pm 1.32$ progeny, equating to $49 \%$ of total eggs available. Fecundity showed relatively consistent declines over the first three weeks, with a $<50 \%$ reduction in parasitism by day 5, and a complete absence of progeny after day 19 .

Life table and demographic parameters

Females fed a honey-water diet began oviposition behavior immediately after eclosion. Females exhibited a mean ovipositional period of $10.10 \pm 0.10$ days with an average post-reproductive period of $20.50 \pm 2.98$ days (Table 1 ). The total progeny produced by a single female ranged from 4 to 89 , averaging $39.70 \pm 5.55$ individuals. The average proportion of female progeny was $92.75 \pm 1.52 \%$ when females were continuously paired with a reproductive male. When housed as a mating pair, the age of the adult female did not significantly influence the sex ratio of progeny $\left(\chi^{2}=1.75\right.$, df $\left.=1, p=0.19\right)$. However, the average proportion of female progeny declined slightly over time from $93.60 \%$ on day 1 to $86.70 \%$ on day 9 . When provided a continuous supply of L. zonatus host eggs, $H$. pennsylvanicus exhibited an intrinsic rate of increase $\left(r_{m}\right)$ of $0.22 \pm 0.02$, suggesting, under suitable conditions, a population can multiply $1.26 \pm 0.03$ times per day with a doubling time $\left(T_{d}\right)$ of $3.68 \pm 0.33$ days. Under these conditions, the average lifetime fecundity of a female $\left(R_{0}\right)$ was $35.70 \pm 4.73$ with a generation time $(T)$ of $17.00 \pm 1.63$ days.

Parasitoid host age viability

Under laboratory conditions, host age did not influence parasitism rates or reproductive output of $H$. pennsylvanicus (Fig. 3). The proportion of L. zonatus nymphs to emerge from exposed eggs was $42.93 \pm 6.20 \%$, with unemerged nymphs accounting for $7.47 \pm 1.50 \%$ of the total host eggs. The proportion of $H$. pennsylvanicus adults to emerge was $30.87 \pm 3.31 \%$. Unemerged wasps accounted for $4.07 \pm 0.27 \%$ of the total host eggs. Host eggs that

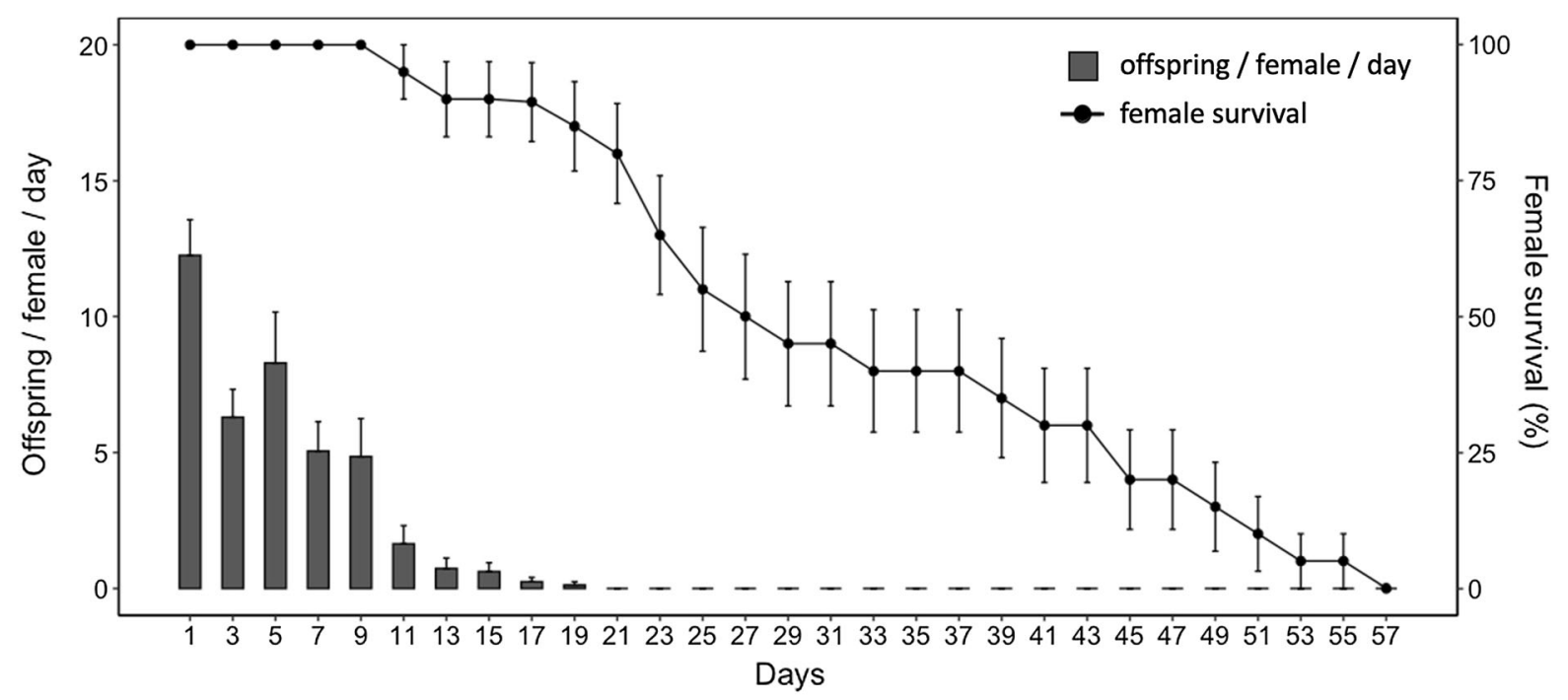

Fig. 2 Mean age-specific fecundity (grey bars) (+ SE) and female survival rate (black dots) ( \pm SE) of Hadronotus pennsylvanicus when provided Leptoglossus zonatus host eggs and fed honey-water ad libitum 
Table 1 Reproductive and demographic attributes (mean $\pm \mathrm{SE}$ ) of Hadronotus pennsylvanicus reared on Leptoglossus zonatus eggs at $25^{\circ} \mathrm{C} \pm 1$, $75 \pm 5 \%$ RH and L:D 16:8, fed honey-water ad libitum
Mean value ( \pm S.E.)

Reproductive parameter

$\begin{array}{lr}\text { Adult female longevity (days) } & 30.60 \pm 3.09\end{array}$

$\begin{array}{lr}\text { Ovipositional period (days) } & 10.10 \pm 0.10\end{array}$

$\begin{array}{lr}\text { Post-reproductive period (days) } & 20.50 \pm 2.98\end{array}$

$\begin{array}{lr}\text { Total progeny (offspring per female) } & 39.70 \pm 5.55\end{array}$

$\begin{array}{lr}\text { Total development time (days) } & 18.65 \pm 0.23\end{array}$

Total aborted progeny (unemerged offspring per female) $\quad 5.80 \pm 1.29$

$\begin{array}{lr}\text { Sex ratio (\% female offspring) } & 92.75 \pm 1.52\end{array}$

Demographic parameter

$\begin{array}{ll}\text { Intrinsic rate of increase }\left(r_{m}\right)\left(\text { days }^{-1}\right) & 0.22 \pm 0.02\end{array}$

Finite rate of increase $(\lambda)$

$1.26 \pm 0.03$

Mean generation time $(T)$ (days)

$17.00 \pm 1.63$

Doubling time $\left(T_{d}\right)$ (days)

$3.68 \pm 0.33$

Net reproductive rate $\left(R_{O}\right)$ (female offspring per female)

$35.70 \pm 4.73$

Gross reproductive rate (GRR) (female offspring per female)

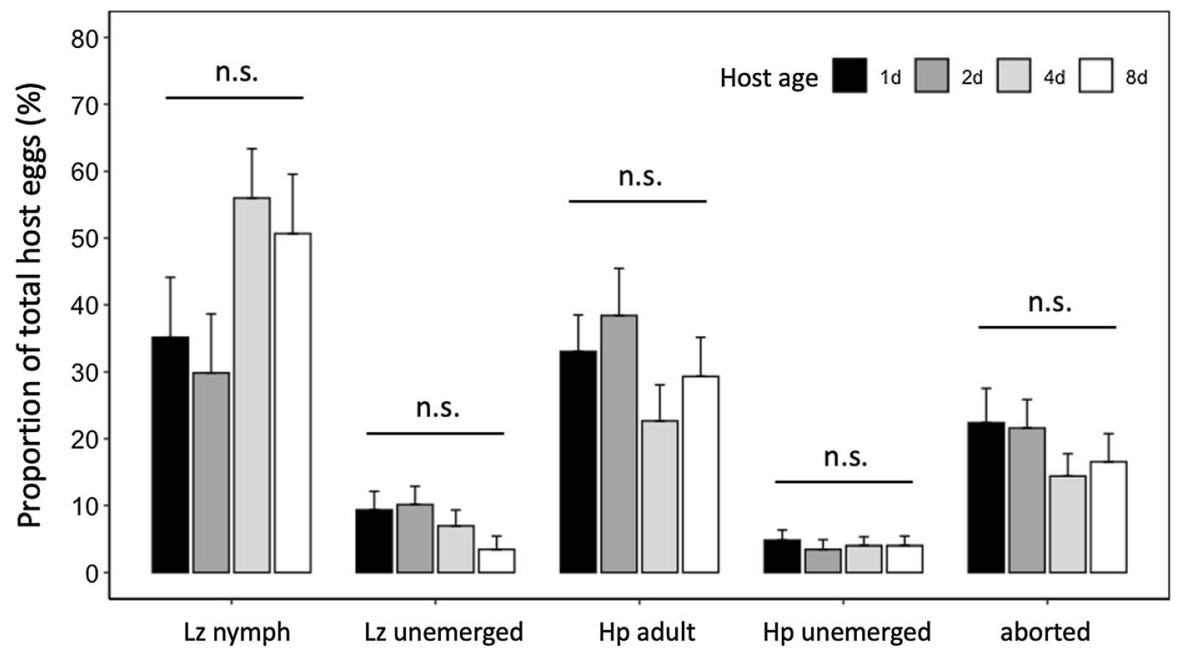

Fig. 3 Proportion of total host eggs (mean + SE) to yield a Leptoglossus zonatus nymph ("Lz nymph"), Hadronotus pennsylvanicus adult ("Hp adult"), unemerged Leptoglossus zonatus ("Lz unemerged"), unemerged Hadronotus

did not yield an L. zonatus nymph nor a $H$. pennsylvanicus adult, and therefore identified as aborted, accounted for $18.73 \pm 1.94 \%$ of the total host eggs. No host feeding behavior was observed throughout the study, concurring with findings from Vogt and Nechols (1993) where authors did not find evidence of $H$. pennsylvanicus feeding on hosts over a cumulative period of $100 \mathrm{~h}$. pennsylvanicus ("Hp unemerged"), or determined "aborted" for eggs of age $1,2,4$, and 8 days old ( $n=15$ per treatment). Bars labelled with "n.s." are not significantly different ( $p>0.05$ ) GLM and Tukey post-hoc test)

Non-reproductive host mortality

Total host egg mortality was highest on day 1, averaging $79.80 \pm 5.73 \%$ (Fig. 4). There was a consistent reduction in total egg mortality over time, with no mortality observed following day 37 . The age of ovipositing female significantly influenced the proportion of non-reproductive egg mortality accounting towards the total host egg mortality $\left(\chi^{2}=86.14\right.$, 


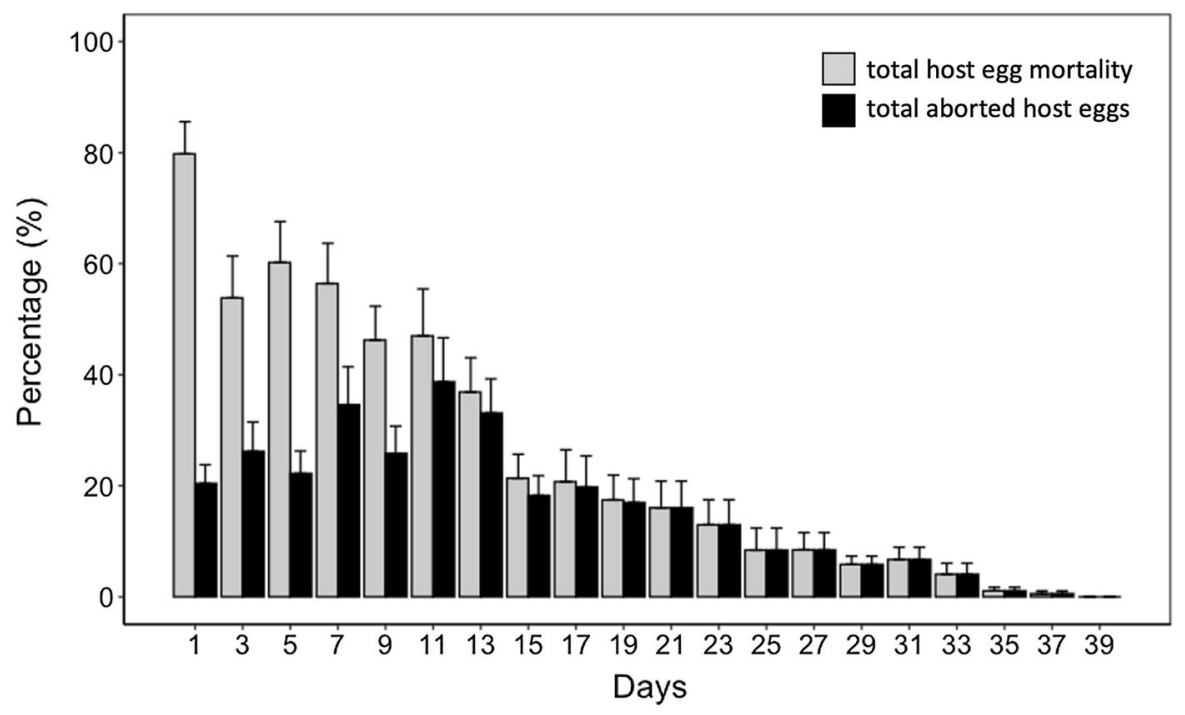

Fig. 4 Proportion of Leptoglossus zonatus host egg mortality $($ mean $+\mathrm{SE})$ in the presence of Hadronotus pennsylvanicus. Eggs that neither yield an Leptoglossus zonatus nymph or adult

$\mathrm{df}=1, \mathrm{p}<0.001)$. The proportion of non-reproductive egg mortality increased with female age from $20.40 \pm 3.37 \%$ on day 1 to the maximum observed $38.74 \pm 7.87 \%$ on day 11 , accounting for $53 \%$ of the total egg mortality observed within the first two weeks of the study. Following day 14, non-reproductive egg mortality accounted for $96 \%$ of the total egg mortality. There were significantly more aborted eggs observed in the presence of adult female wasps $\left(\chi^{2}=33.25\right.$, df $=1, \mathrm{p}<0.001)$. In the absence of a female wasp, only $2.20 \pm 0.61 \%$ of eggs were determined aborted.

\section{Discussion}

Hadronotus pennsylvanicus is a long-lived species, capable of surviving $30.60 \pm 3.09$ days under continuous reproductive opportunity in laboratory conditions. Under these conditions, access to a carbohydrate rich diet has shown to be vital for the survival of $H$. pennsylvanicus (Olson and Nechols 1995; Sabbatini Peverieri et al. 2012), and, here, honey-water deprived wasps expired shortly after eclosion. As such, the establishment and maintenance of $H$. pennsylvanicus in agricultural landscapes may be contingent on the availability of suitable carbohydrate food resources such as floral nectar or insect honeydew. Under laboratory conditions, both male and female wasp were determined aborted (black bars), which contributed to the total host egg mortality induced by parasitism (grey bars)

parasitoids lived significantly longer in the absence of host eggs. Here, there was $74 \%$ reduction in female longevity when wasps were held under continuous reproductive opportunity. This trend was more pronounced in females than males, where only a $55 \%$ reduction in longevity was observed. These observations concur with findings reported in Martel et al. (2019) for Gryon aetherium Talamas (reported as G. gonikopalense Sharma), where a $>50 \%$ reduction in female longevity was reported when provided a continuous supply of host eggs. Such reproductive cost on longevity may be attributed to the energy expenditure incurred during egg manufacturing for females under continuous reproductive opportunity (Benelli et al. 2017). While mating status has shown to reduced female parasitoid longevity, little is known of the reproductive costs associated with male longevity and further investigation is required.

Similar to observations found in Nechols et al. (1989) and Sabbatini Peverieri et al. (2012), $H$. pennsylvanicus exhibited a short pre-oviposition time period, with peak female fecundity reached on day 1 following emergence. When reared on Leptoglossus sp. hosts, $H$. pennsylvanicus females exhibited an initial spike in parasitism rates, with a second peak after five days of reproductive opportunity (Sabbatini Peverieri et al. 2012). Egg limitation appears to be a limiting factor on lifetime fecundity for female $H$. 
pennsylvanicus (Sabbatini Peverieri et al. 2012; Cornelius et al. 2018). Here, we observed a rapid decline in fecundity over time, with more than $90 \%$ of offspring being produced within the first two weeks of a female's life. The total progeny produced per female $H$. pennsylvanicus $(39.70 \pm 5.55$ when provided host eggs every other day) was less than that reported on hosts A. tristis $(80.7 \pm 36$ when provided host daily; Nechols et al. 1989) and L. occidentalis (144.55 \pm 50.66 when provided host daily; Sabbatini Peverieri et al. 2012). However, both the intrinsic and finite rate of increase of $H$. pennsylvanicus when reared on L. zonatus eggs concurred with observations from hosts L. occidentalis and A. tristis (Nechols et al. 1989; Sabbatini Peverieri et al. 2012). Similarly, observations on mean generation time (17.00 days) were similar to those found in Nechols et al. (1989) and Sabbatini Peverieri et al. (2012). Results in this study suggest population growth attributes of $H$. pennsylvanicus on L. zonatus are congruent with those identified from alternative hosts, and similar to trends from other species of Hadronotus and Gryon, including H. clavigrallae Mineo, $H$. gonikopalense, $H$. gallardoi (Bréthes), and H. philippinense (Ashmead) (Dasilao and Arakawa 2004; Canto-Silva et al. 2006; Martel et al. 2019; Romeis et al. 2000). Given that these observations show similar trends in life history traits, data obtained on the total progeny produced, and therefore used to calculate estimates to $R O$ and $G R R$, are likely underestimated given that wasps were only provided eggs every other day for oviposition as opposed to daily, as demonstrated in Nechols et al. (1989) and Sabbatini Peverieri et al (2012). Here, providing a fewer number of host eggs during the wasps ovipositional period would result in fewer progeny produced over the course of the females lifetime. While these results may help elucidate trends on parasitoid fitness, future research would benefit to assess the reproductive capacity of $H$. pennsylvanicus when provided L. zonatus host eggs daily for more accurate comparisons in lifetime fecundity between alternative host species.

Hadronotus pennsylvanicus maintained a greater average proportion of female progeny $(92.75 \pm 1.52 \%)$ when provided $L$. zonatus eggs than when reared on hosts L. occidentalis $(72.45 \%)$ and $A$. tristis (78\%) (Nechols et al. 1989; Sabbatini Peverieri et al. 2012), and higher than Gryon spp. on alternative hemipteran hosts (Dasilao and Arakawa, 2004; Canto-
Silva et al. 2006; Martel et al. 2019; Romeis et al. 2000) when reared under similar laboratory conditions. H. pennsylvanicus exhibited a slower decline in the proportion of female progeny over time when provided L. zonatus eggs in comparison to $L$. occidentalis (Sabbatini Peverieri et al. 2012). Sabbatini Peverieri et al. (2012) accounted for such trends in sex ratio to be due to sperm depletion in females over time despite maintaining copulation opportunity by replacing expired males throughout the female's lifetime. However, the influence of sperm depletion on reproductive output is poorly documented for scelionid wasps, and thus requires further investigation. Furthermore, this would suggest that $H$. pennsylvanicus only mates once after eclosion. Despite observations of copulation occurring shortly after introducing female with male wasps, this study did not specifically document mating behavior following day 1 of the study, and further research is needed to confirm such hypotheses on $H$. pennsylvanicus mating behavior. While parasitoid fecundity ultimately relies on availability of hosts, exhibiting a high female-skewed sex ratio in progeny would likely benefit population growth rates and reproductive capacity in applied settings.

The quality of a host in relation to its age may be highly variable in field settings (Vinson 1998). Egg parasitoids may favor younger hosts given they could potentially provide a longer duration of time for parasitoid offspring to development. This trend was observed for other Hadronotus spp., such as $H$. gallardoi, H. flavipes (reported as G. nixoni Masner), $H$. clavigrallae, and H. obesus Masner (Morrill and Almazon 1990; Romeis et al. 2000; Hirose et al. 2003; da Rocha et al. 2006a, b). However, host egg age did not influence parasitism nor reproductive output of $H$. pennsylvanicus on L. zonatus. Sabbatini Peverieri et al. (2013) similarly found that parasitoid fitness was not influenced by the age of the host nor when eggs were stored at low temperatures (Sabbatini Peverieri et al. 2014). Successful wasp eclosion was highest early in the ovipositing female's lifetime. However, this trend consistently declined over time. The proportion of aborted eggs increases over time, ultimately accounting for the majority of total host egg mortality following day 11 . This may suggest a persistence in parasitism behavior despite a potential egg limitation being reached in ovipositing females. Given non-reproductive egg mortality may play a 
significant role in biocontrol programs (Abram et al. 2016, 2019), future research would benefit to document parasitoid egg load under these reproductive conditions to better understand the limits of egg maturation in $H$. pennsylvanicus.

Under laboratory conditions, $H$. pennsylvanicus exhibits suitable biological and reproductive traits suggesting potential for use in biocontrol programs for L. zonatus. However, it is important to note that demographic values are valid only when considering stable age populations, and therefore may not accurately reflect populations in applied settings. While $H$. pennsylvanicus and other egg parasitoids, such as Ooencyrtus Ashmead (Encyrtidae), Anastatus Motschulsky (Eupelmidae) and Trissolcus Ashmead (Scelionidae), may help contribute to lowering $L$. zonatus densities (Mitchell and Mitchell, 1986; Marchiori, 2002; Xiao and Fadamiro, 2010; Maltese et al. 2012), resident populations have not provided sufficient control of the pest in orchards. In California, overwintered adult L. zonatus disperse early in the season and attack almond (mid-February to March) and pistachio (April to mid-May) resulting in crop damage (Daane et al. 2005; Zalom et al. 2018). Here, future research would benefit by understanding the phenology of both pest and parasitoid populations in relation to tree nut development to identify effective methods for bolstering $H$. pennsylvanicus populations to improve parasitism rates in the field. This information would enable a better understanding of how populations respond to resource availability and if biocontrol can effectively reduce pest pressure at times of crop vulnerability. Improved knowledge of the ecology and behavior of the egg parasitoid $H$. pennsylvanicus in relation to host $L$. zonatus would allow for the development of more targeted, and likely more successful IPM strategies to improve biocontrol of this economically important pest in California orchards.

Acknowledgements We would like to thank Dani Evans, Tyler Colombero, Javier Herrera, and German Camacho for laboratory support. Bioassays and data collections were carried out with assistance from Socorro Cisneros. DNA extractions were conducted by Jonathan Bremer. Sequencing and Genbank uploads were performed by Lynn Combee, Cheryl Roberts, and Matthew Moore. This work was supported by the Western Sustainable Agriculture Research GW20-207, the Robert and Peggy van den Bosch Memorial Scholarship, California Pistachio Research Board No. ENT-2019-003, California Department of Food and Agriculture's Specialist Crop Block
Grant No. 19-0001-041-SF, and USDA National Institute of Food and Agriculture Hatch Project 1022920. Elijah Talamas was supported by the Florida Department of Agriculture and Consumer Services, Division of Plant Industry.

Author contributions RS and HW led study design, laboratory work, analyses, and manuscript preparation. KD contributed to study design, and manuscript preparation. HW, KD and RS secured funding. ET contributed to parasitoid identification and manuscript preparation.

Data availability Raw data are available upon request.

Code availability Analysis code is deposited in Github (https://github.com/rstraser/Hadronotus_biocontrol_eval).

\section{Declarations}

Conflict of interest The authors declare that they have no conflict of interest.

Ethical approval As no humans or other mammal subjects were involved in this research, no ethics approvals were required for this study.

Informed consent All authors consent to participate in publication of these data of this work.

Consent to participate All authors consent to participate in publication of these data.

Consent for publication All authors consent to participate in publication of this work.

Open Access This article is licensed under a Creative Commons Attribution 4.0 International License, which permits use, sharing, adaptation, distribution and reproduction in any medium or format, as long as you give appropriate credit to the original author(s) and the source, provide a link to the Creative Commons licence, and indicate if changes were made. The images or other third party material in this article are included in the article's Creative Commons licence, unless indicated otherwise in a credit line to the material. If material is not included in the article's Creative Commons licence and your intended use is not permitted by statutory regulation or exceeds the permitted use, you will need to obtain permission directly from the copyright holder. To view a copy of this licence, visit http://creativecommons.org/licenses/by/4.0/.

\section{References}

Abram PK, Brodeur J, Burte V, Boivin G (2016) Parasitoidinduced host egg abortion: an underappreciated component of biological control services provided by egg parasitoids. Biol Control 98:52-60

Abram PK, Brodeur J, Urbaneja A, Tena A (2019) Nonreproductive effects of insect parasitoids on their hosts. Annu Rev Entomol 64:259-276 
Abram PK, Mills NJ, Beers EH (2020) Review: Classical biological control of invasive stink bugs with egg parasitoids-what does success look like? Pest Manage Sci 76:1980-1992

Bates SL, Borden JH (2004) Parasitoids of Leptoglossus occidentalis Heidemann (Heteroptera: Coreidae) in British Columbia. J Entomol Soc B C 101:143-144

Bates D, Mächler M, Bolker B, Walker S (2015) Fitting linear mixed-effects models using lme4. J Stat Softw 67:1-48

Benelli G, Giunti G, Tena A, Desneux N, Caselli A, Canale A (2017) The impact of adult diet on parasitoid reproductive performance. J Pest Sci 90:807-823

Brailovsky H (2014) Illustrated key for identification of the species included in the genus Leptoglossus (Hemiptera: Heteroptera: Coreidae: Coreinae: Anisoscelini), and descriptions of five new species and new synonyms. Zootaxa 3794:143-178

Canto-Silva CR, Romanowski HP, Redaelli LR (2006) Reproductive parameters and longevity of Gryon gallardoi (Brethes) (Hymenoptera: Scelionidae) parasitizing Spartocera dentiventris (Berg) (Hemiptera: Coreidae) eggs. Braz J Biol 66:19-24

Cornelius ML, Hu JS, Vinyard BT (2018) Comparative study of egg parasitism by Gryon pennsylvanicum (Hymenoptera: Scelionidae) on two squash bug species Anasa tristis and Anasa armigera (Hemiptera: Coreidae). Environ Entomol 47:1451-1458

da Rocha L, Kolberg R, de Mendonça MS, Redaelli LR (2006a) Body size variation in Gryon gallardoi related to age and size of the host. BioControl 52:161-173

da Rocha L, Kolberg R, de Mendonça MS, Redaelli LR (2006b) Effects of egg age of Spartocera dentiventris (Berg) (Hemiptera: Coreidae) on parasitism by Gryon gallardoi (Brethes) (Hymenoptera: Scelionidae). Neotrop Entomol 35:654-659

Daane KM, Yokota G, Krugner R, Steffan S, da Silva P, Beede R, Bentley W, Weinberger G (2005) Large bugs damage pistachio nuts most severely during midseason. Calif Agric 59:95-102

Daane KM, Yokota G, Bentley W, Weinberger G, Millar J, Beede RH (2016) Stink bugs and leaffooted bugs. Pistachio Prod. Man., publication 3545, pp 225-238

Daane KM, Yokota GY, Wilson H (2019) Seasonal dynamics of the leaffooted bug Leptoglossus zonatus and its implications for control in almonds and pistachios. Insects 10:255

Dasilao AO, Arakawa R (2004) Reproductive capacity and host handling behavior of Gryon philippinense (Ashmead) (Hymenoptera: Scelionidae), a solitary egg parasitoid of the winter cherry bug, Acanthocoris sordidus Thunberg (Hemiptera: Coreidae). Appl Entomol Zool 39:263-269

Foresti J, Bastos CS, Fernandes FL, da Silva PR (2017) Economic injury levels and economic thresholds for Leptoglossus zonatus (Dallas) (Hemiptera: Coreidae) infesting seed maize. Pest Manag Sci 74:149-158

Grimm C (1999) Evaluation of damage to physic nut (Jatropha curcas) by true bugs. Entomol Exp Appl 92:127-136

Haviland DR, Bentley WJ, Beede RH, Daane KM (2018) Pistachios: insects and mites. In: University of California IPM pest management guidelines, Publication 3461; University of California, Agriculture and Natural Resources: Oakland, CA
Hirose Y, Ehler LE, Hirose Y (2003) Influence of host age on patch use by a quasi-gregarious egg parasitoid. Environ Entomol 32:789-796

Hothorn T, Bretz F, Westfall P (2008) Simultaneous inference in general parametric models. Biom J 50:346-363

Joyce AL, Higbee BS, Haviland DR, Brailovsky H (2017) Genetic variability of two leaffooted bugs, Leptoglossus clypealis and Leptoglossus zonatus (Hemiptera: Coreidae) in the Central Valley of California. J Econ Entomol 110:2576-2589

Joyce AL, Barman AK, Doll D, Higbee BS (2019) Assessing feeding damage from two leaffooted bugs, Leptoglossus clypealis Heidemann and Leptoglossus zonatus (Dallas) (Hemiptera: Coreidae), on four almond varieties. Insects $10: 333$

Maltese M, Caleca V, Guerrieri E, Strong WB (2012) Parasitoids of Leptoglossus occidentalis Heidemann (Heteroptera: Coreidae) recovered in western North America and first record of its egg parasitoid Gryon pennsylvanicum (Ashmead) (Hymenoptera: Platygastridae) in California. Pan-Pac Entomol 88:347-355

Marchiori CH (2002) Natural enemies of Leptoglossus zonatus (Dallas, 1852) (Hemiptera: Coreidae) on maize in Itumbiara, Goias. Biotemas 15:69-74

Martel G, Augé M, Talamas E, Roche M, Smith L, Sforza R (2019) First laboratory evaluation of Gryon gonikopalense (Hymenoptera: Scelionidae), as potential biological control agent of Bagrada hilaris (Hemiptera: Pentatomidae). Biol Control 135:48-56

Masner L (1983) A revision of Gryon Haliday in North America (Hymenoptera: Proctotrupoidea: Scelionidae). Can Entomol 115:123-174

Michailides T (1989) The 'Achilles heel' of pistachio fruit. Calif Agric 43:10-11

Michailides TJ, Morgan DP (2016) Association of Botryosphaeria panicle and shoot blight of pistachio with injuries of fruit caused by Hemiptera insects and birds. Plant Dis 100:1404-1413

Michailides T, Rice RE, Ogawa JM (1987) Succession and significance of several hemipterans attacking a pistachio orchard. J Econ Entomol 8(2):398-406

Mitchell PL, Mitchell FL (1986) Parasitism and predation of leaffooted bug (Hemiptera: Heteroptera: Coreidae) eggs. Ann Entomol Soc Am 79:854-860

Morrill WL, Almazon LP (1990) Effect of host plant species and age of rice bug (Hemiptera: Alydidae) eggs on parasitism by Gryon nixoni (Hymenoptera: Scelionidae). J Entomol Sci 25:450-452

Nechols JR, Tracy JL, Vogt EA (1989) Comparative ecological studies of indigenous egg parasitoids (Hymenoptera: Scelionidae: Encyrtidae) of the squash bug, Anasa tristis (Hemiptera: Coreidae). J Kans Entomol Soc 62:177-188

Olson DL, Nechols JR (1995) Effects of squash leaf trichome exudates and honey on adult feeding, survival, and fecundity of the squash bug (Heteroptera: Coreidae) egg parasitoid Gryon pennsylvanicum (Hymenoptera: Scelionidae). Environ Entomol 24:454-458

Peverieri GS, Furlan P, Benassai D, Caradonna S, Strong WB, Roversi PF (2013) Host egg age of Leptoglossus occidentalis (Heteroptera: Coreidae) and parasitism by Gryon 
pennsylvanicum (Hymenoptera: Platygastridae). J Econ Entomol 106:633-640

R Core Team (2019) R: a language and environment for statistical computing. R Foundation for Statistical Computing, Vienna. https://www.r-project.org/

Ramírez-Ahuja ML, Garza-Gonzalez E, Talamas EJ, GomezGovea MA, Rodriguez-Perez MA, Zambrano-Robledo P, Rebollar-Tellez EA, Rodríguez-Sanchez IP (2020) Parasitoids of chrysopidae eggs in Culiacan, Mexico. Insects 11:849

Rivero SHT, Hernández AG (2009) Species, seasonal occurrence, and natural enemies of stink bugs and leaffooted bugs (Hemiptera: Pentatomidae, Coreidae, Largidae) in pecans. Southwest Entomol 34:305-318

Romeis J, Shanower T, Madhuri K (2000) Biology and field performance of Gryon clavigrallae (Hymenoptera: Scelionidae), an egg parasitoid of Clavigralla spp. (Hemiptera: Coreidae) in India. Bull Entomol Res 90:253-263

Roversi PF, Sabbatini Peverieri G, Maltese M, Furlan P, Strong WB, Caleca V (2013) Pre-release risk assessment of the egg-parasitoid Gryon pennsylvanicum for classical biological control of Leptoglossus occidentalis. J Appl Entomol 138:27-35

Sabbatini Peverieri G, Furlan P, Simoni S, Strong W, Roversi P (2012) Laboratory evaluation of Gryon pennsylvanicum (Ashmead) (Hymenoptera: Platygastridae) as a biological control agent of Leptoglossus occidentalis Heidemann (Heteroptera: Coreidae). Biol Control 61:104-111

Sabbatini Peverieri G, Furlan P, Benassai D, Strong WB, Roversi PF (2014) Long-term storage of eggs of Leptoglossus occidentalis for the mass-rearing of its parasitoid Gryon pennsylvanicum. BioControl 60:293-306

Stahl JM, Scaccini D, Pozzebon A, Daane KM (2020) Comparing the feeding damage of the invasive brown marmorated stink bug to a native stink bug and leaffooted bug on California pistachios. Insects 11:688

Talamas EJ, Bremer JS, Moore MR, Bon MC, Lahey Z, Roberts CG, Combee LA, McGathey N, van Noort S, Timokhov AV, Hougardy E, Hogg B (2021) A maximalist approach to the systematics of a biological control agent: Gryon aetherium Talamas, sp. nov. (Hymenoptera, Scelionidae). J Hymenopt Res 87:323-480
Vinson S (1998) The general host selection behavior of parasitoid Hymenoptera and a comparison of initial strategies utilized by larvaphagous and oophagous species. Biol Control 11:79-96

Vogt E, Nechols J (1993) The influence of host deprivation and host source on the reproductive biology and longevity of the squash bug egg parasitoid Gryon pennsylvanicum (Ashmead) (Hymenoptera: Scelionidae). Biol Control 3:148-154

Xiao YF, Fadamiro HY (2010) Evaluation of damage to satsuma mandarin (Citrus unshiu) by the leaffooted bug, Leptoglossus zonatus (Hemiptera: Coreidae). J Appl Entomol 134:694-703

Yasuda K (1998) Function of the male pheromone of the leaffooted plant bug, Leptoglossus australis (Fabricius) (Heteroptera: Coreidae) and its kairomonal effect. Jpn Agric Res Q 32:161-165

Zalom FG, Haviland DR, Symmes ET, Tollerup K (2018) Almonds: insects and mites. University of California IPM pest management guidelines, Publication 3431 ed. University of California, Agriculture and Natural Resources: Oakland, CA, USA

Robert K. Straser is a $\mathrm{PhD}$ candidate in the Department of Entomology at University of California, Riverside, USA. This article is part of his dissertation, which focuses on methods to improve biocontrol of Leptoglossus zonatus.

Kent M. Daane specializes in developing sustainable pest management programs. His research includes classical biocontrol, insect-plant interactions, and the biology of natural enemies.

Elijah Talamas is a specialist in taxonomy, morphology, and evolution of platygastroid wasps, especially groups with potential use for biocontrol.

Houston Wilson specializes in the development, evaluation and adoption of sustainable pest management practices for orchards and vineyards. 